\title{
Improving tribological and anti-bacterial properties of titanium external fixation pins through surface ceramic conversion
}

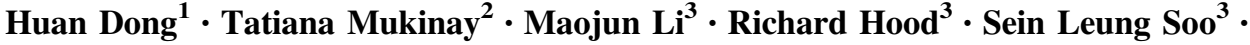 \\ Simon Cockshott ${ }^{1} \cdot$ Rachel Sammons ${ }^{4} \cdot$ Xiaoying $\mathbf{L i}^{2}$
}

Received: 16 August 2016 / Accepted: 14 November 2016 / Published online: 24 November 2016

(C) The Author(s) 2016; This article is published with open access at Springerlink.com

\begin{abstract}
In this study, an advanced ceramic conversion surface engineering technology has been applied for the first time to self-drilling Ti6Al4V external fixation pins to improve their performance in terms of biomechanical, biotribological and antibacterial properties. Systematic characterisation of the ceramic conversion treated Ti pins was carried out using Scanning electron microscope, X-ray diffraction, Glow-discharge optical emission spectroscopy, nano- and micro-indentation and scratching; the biomechanical and bio-tribological properties of the surface engineered Ti pins were evaluated by insertion into high density bone simulation material; and the antibacterial behaviour was assessed with Staphylococcus aureus NCTC 6571. The experimental results have demonstrated that the surfaces of Ti6Al4V external fixation pins were successfully converted into a $\mathrm{TiO}_{2}$ rutile layer $(\sim 2 \mu \mathrm{m}$ in thickness) supported by an oxygen hardened case ( $\sim 15 \mu \mathrm{m}$ in thickness) with very good bonding due to the in-situ conversion nature. The maximum insertion force and temperature were reduced from $192 \mathrm{~N}$ and $31.2{ }^{\circ} \mathrm{C}$ when using the untreated pins to $182 \mathrm{~N}$ and $26.1{ }^{\circ} \mathrm{C}$ when the ceramic conversion treated pins were tested. This is mainly due to the significantly increased hardness (more than three times) and the effectively enhanced wear resistance of
\end{abstract}

Huan Dong

dongh100@gmail.com

Royal Derby Hospital, Derby DE22 3NE, UK

2 School of Metallurgy and Materials, University of Birmingham, Birmingham B15 2TT, UK

3 School of Engineering, University of Birmingham, Birmingham B15 2TT, UK

4 School of Dentistry, University of Birmingham, Birmingham B4 $6 \mathrm{NN}, \mathrm{UK}$ the cutting edge of the self-drilling Ti pins following the ceramic conversion treatment. The antibacterial tests also revealed that there was a significantly reduced number of bacteria isolated from the ceramic conversion treated pins compared to the untreated pins of around $50 \%$ after $20 \mathrm{~h}$ incubation, $P<0.01(0.0024)$. The results reported are encouraging and could pave the way towards highperformance anti-bacterial titanium external fixation pins with reduced pin-track infection and pin loosing.

\section{Introduction}

External fracture fixation is a common orthopaedic procedure that is used increasingly in a variety of trauma settings. These include highly comminuted fractures, open fractures, fractures associated with gross soft tissue damage or in the multiply injured patient. This method of fixation can be used either as a temporising measure before definitive internal fixation or as definitive treatment itself. External fixation entails the use of percutaneously placed transosseous pins and/or wires secured to external scaffolding to provide support to a limb. For example, an Ilizarov frame can provide stability to the fracture, protect skin grafts, and allow access to adjacent soft tissue. These percutaneous K-wires cause minimal disruption of the blood supply and soft tissues through the zone of injury [1]. Now, external fixation has evolved from being used primarily as a last resort fixation method to becoming a main stream technique used to treat a myriad of bone and soft tissue pathologies.

A well designed pin is essential to ensure a solid fixation, ease of insertion and reduce risk of complications. Stainless steel and titanium self-drilling/self-tapping Schanz pins 
offer a one-step insertion where pre-drilling is not required because the self-drilling tip acts like a new, sharp drill bit. Combined with the unique cutting geometry, this one-step procedure allows reduced insertion time and temperature for optimal performance [2].

Austenitic stainless steels have been the material of choice for external fixation pins owing to their attractive combination of excellent corrosion resistance, good mechanical properties and adequate biocompatibility coupled with their outstanding formability and cost-effectiveness [3]. However, pin track infection is a common complication in stainless steel external fixation systems with infection rates ranging from $2 \%$ to as high as $30 \%$ [4]. This is because the pin entry site is constantly open to the environment and presents a critical interface between the external stainless steel pin and internal soft tissues and bone. The critical consequences of infected pin sites are pin loosening, fracture destabilisation and osteomyelitis, thus leading to additional surgical interventions and delayed or non-union [5]. Indeed, how to combat multi-resistant bacteria has become one of the greatest challenges in the treatment of post-operative infections.

Antibacterial or self-disinfecting surfaces have progressively become a primary strategy in the fight against medical device-associated infections [6]. Antibacterial surfaces can be created by coating surfaces with silver since silver and its compounds have a broad-spectrum of antimicrobial activities. For instance, pure Ag has been used to coat stainless steel surfaces. However, it has been reported that no statistically significant difference in the clinical outcomes of Ag-coated and uncoated steel fixation pins could be observed [7]. Some attempts have also been made to develop Ag-containing nanocomposite coatings with increased hardness [5]. However, there is a lack of controlled release kinetics from the Ag-containing coatings. The major concerns over Ag-containing composite coatings under tribological application are how to ensure adequate bonding between the coating and the substrate. Failure of such Ag-containing coatings will lead to fast leaching of $\mathrm{Ag}$ ions and may result in toxicity [8].

Alternatively, the track infection caused by stainless steel pins could be partially addressed by replacing stainless steel with titanium and titanium fixation pins are now commercially available. This is mainly because the $\mathrm{TiO}_{2}$ oxide layer formed on titanium and its alloys has shown some extent of anti-bacterial efficacy [9]. Some researchers have attempted to further increase the anti-bacterial efficacy of $\mathrm{Ti}$ and its alloys by coating their surfaces with an antibacterial coating $[10,11]$.

Anodising has long been used to form a thin $(<0.1 \mu \mathrm{m})$ and compact $\mathrm{TiO}_{2}$ film on $\mathrm{Ti}$ surfaces when the anodic oxide is insoluble in the electrolyte. More recently, $\mathrm{TiO}_{2}$ nanotube arrays are generated when the anodic oxide is moderately soluble in the electrolyte, which showed a high antibacterial efficacy [12]. However, their durability under wear conditions is low in view of their limited thickness and low hardness (373HV) [13]. As a wet chemical surface coating technology, sol-gel is employed by some researchers to produce a dense and smooth anti-bacterial $\mathrm{TiO}_{2}$ layers $(<10 \mu \mathrm{m})$ on $\mathrm{Ti}$ surfaces without affecting the surface morphology at the micrometric scale. However, this technique is not an economic solution to complex 3D surfaces due to dip or spray coating, the bonding to the substrate is normally low, and cracking is a major technical challenge for sol-gel coating [14].

A thick $\mathrm{TiO}_{2}$ coating can be produced by plasma electrolytic oxidation $(<40 \mu \mathrm{m})$ or thermal spraying $(100-400$ $\mu \mathrm{m})$. These two techniques present several advantages such as high deposition rate, relatively low-cost and possibility for doping with metal nanoparticles (such as Ag). However, it is difficult, if not impossible to produce dense and pure $\mathrm{TiO}_{2}$ coating with a smooth surface by these two techniques [15].

As for all coating technologies, the bonding of these coatings to titanium substrate is a major concern for such bio-tribological devices as self-drilling/self-tapping Schanz pins. In addition, it is well-known that titanium and its alloys are characterised by poor mechanical properties in terms of low hardness and low load bearing capacity. Therefore, without strong mechanical support from the substrate, the very thin (nanometric) $\mathrm{TiO}_{2}$ films formed in air at room temperature [16] or the anti-bacterial coatings produced by the above coating methods can be damaged by tribological interaction due to the so-called "thin egg-shell effect" [17]. This led to the loss of the anti-bacterial property and costly duplex treatments were developed to increase the durability of thin antibacterial coatings [18]. In addition, Ti alloys have reputation of poor tribological properties in terms of low hardness, high friction and strong adhesive wear $[19,20]$. Therefore, from a bio-mechanics point of view, the wear of $\mathrm{Ti}$ self-drilling tip or cutting edge necessitates an increased insertion force [1]. This will in turn result in increased temperature at bone-pin surface during insertion, which would cause damage to the bone and retard its healing after operation [21].

To this end, the present paper reports an novel approach to generate a multi-functional surface for titanium Schanz pins by converting their $\mathrm{Ti}$ surfaces into $\mathrm{a} \mathrm{TiO}_{2}$ ceramic layer through thermal oxidation of $\mathrm{Ti}$ in an oxygen-containing atmosphere. In the meantime, oxygen diffuses into the subsurface to form a hard oxygen diffusion hardened case. This oxygen diffusion hardened case can provide a strong mechanical support to the surface $\mathrm{TiO}_{2}$ ceramic layer, thus effectively conferring a high load bearing capacity of the CCT treated $\mathrm{Ti}$ surafces. Most importantly, the bonding between the surface ceramic layer and the oxygen diffusion 
hardened subsurface is strong due to the in-situ conversion nature of the formation of the $\mathrm{TiO}_{2}$ ceramic layer. In addition, this ceramic conversion treatment (CCT) is fully environmentally friendly and cost-effective. This is because unlike sole-gel, anodising or plasma electrolytic oxidation, neither chemical precursors nor toxic by-products are involved in the CCT; unlike thermal spraying, all the 3D surfaces with a complex geometry can be treated.

This CCT was developed from University of Birmingham [22], [23] and has been successfully used for motor sports for tribological property enhancement [24]. However, the potential of this CCT technique has not been explored for medical devices. This can pave the way towards highperformance anti-bacterial titanium external fixation pins because the CCT process could significantly increase their surface hardness and load bearing capacity, significantly reduce their friction and wear, and confer high anti-bacterial efficacy to their surfaces.

\section{Materials and methods}

\subsection{Substrate materials}

Ti6Al4V coupon samples with a thickness of about $5 \mathrm{~mm}$ were cut from hot rolled and annealed bar (supplied by IMI Titanium Ltd) of $25.4 \mathrm{~mm}$ (i.e., $1 \mathrm{inch}$ ) in diameter for ceramic conversion treatments. The treated coupon samples were used for microstructure and properties characterisation. Commercial Ti6Al4V titanium alloy self-drilling/selftapping pins (Apex 5018-6-150S) were used for ceramic conversion treatment under optimised conditions derived from the characterisation of CCT treated coupon samples. The diameter of the thread/shaft, total length and thread length were 5,150 and $50 \mathrm{~mm}$ respectively.

\subsection{CCT}

Coupon samples were carried out the treatments between temperatures of 500 to $850{ }^{\circ} \mathrm{C}$ for times of 10 to $100 \mathrm{~h}$. The treatments were carried out in a controlled atmosphere containing $20 \%$ oxygen and $80 \%$ nitrogen under $100 \mathrm{~Pa}$ to convert the titanium surface into an oxide layer and to introduce oxygen into the subsurface to form an oxygen solid solution hardened diffusion case. The treatment temperature and time are two important factors affecting the surface layer quality and tribological performances, thus the treatment atmosphere and the pressure were kept constant. Based on the systematic optimisation work on the coupon samples a patented [22, 23] treatment conditions of $600{ }^{\circ} \mathrm{C}$, $85 \mathrm{~h}$ was selected for the titanium alloy pins.

\subsection{Characterisation of CCT treated coupons and the pins}

The microstructure of CCT treated Ti6Al4V coupon samples was fully characterised using glow discharge optical emission spectrometry (GDOES, GDA650HR, Spectrma) to measure the composition depth profiles of oxygen, titanium, vanadium, and aluminium. A Philips PW $1050 \mathrm{X}$-ray spectrometer (with $\mathrm{Cu} \mathrm{K}_{\alpha}$ radiation) was used to identify the phases present in the treated specimens. A Jeol 6300 SEM equipped with an EDX facility was used to examine the cross-sectional microstructure of the CCT treated Ti6Al4V surface. Surface layer microstructure and phase composition of the $600{ }^{\circ} \mathrm{C}, 85 \mathrm{~h}$ treated sample was examined by transmission electron microscope (TEM) using a JEOL 4000FX. The TEM specimens were prepared perpendicular to the surface (XTEM). Two slabs of surface treated samples were cut and glued together as a 'sandwich'. This sandwiched sample was cut cross-sectional into $1 \mathrm{~mm}$ thickness slices and they were then mechanical thinned, dimpled and finally ion-beam milled to penetration.

The mechanical properties in terms of hardness, Young's modulus of the surface oxide layer formed by CCT were probed using a Vantage Nano indentation machine with the typical resolutions of $0.1 \mathrm{~nm}$ in displacement and $100 \mathrm{nN}$ in force. The hardness profile of treated Ti6Al4V was obtained on polished metallographic sections normal to the surface by a Leitz Miniload hardness tester with a Knoop indenter under a load of $25 \mathrm{gf}(0.24 \mathrm{~N})$. In view of the scatter of the microhardness data, especially in two phase microstructure regions, the points plotted was a mean of five measurements made at the same depth with the standard deviation as the error bars.

The adhesion of the surface oxide layer to the substrate was studied by friction monitored scratch testing using a Teer ST-200 scratch tester. During the test a load was applied to the Rockwell'C' spherical cone diamond indenter which increased linearly at a loading rate of $20 \mathrm{~N} / \mathrm{min}$, the table moved at the speed of $4 \mathrm{~mm} / \mathrm{min}$. The load at which the friction force rapidly increases, corresponding to the delamination of the surface oxide layer, is defined as the critical load. The failure mechanism was further studied by SEM observation.

\subsection{Insertion test in bone simulation material}

The biomechanical and bio-tribological properties of CCT treated Ti6Al4V pins were evaluated by insertion tests using bone simulating material. This is mainly because the mechanical properties (such as hardness and wear) of fresh animal bones depend highly on the type, the position and the freshness of the bones. Hence, it is difficult, if not impossible, to compare the insertion behaviour of untreated 
and treated titanium pins using a fresh animal bone. Therefore, SAWBONES ${ }^{\circledR}$ (Europe AB, Sweden) highdensity short fibre filled resin (density $2.5 \%$, compressive strength, $157 \mathrm{MPa})$ bone substitute blocks $(30 \times 17 \times 4 \mathrm{~mm})$ were used to simulate pin insertion into cortical bone. An industrial drilling machine (Mazak Vertical Centre Smart 430A) was employed to conduct the insertion test under a constant feed rate (i.e., insertion speed) of $25 \mathrm{~mm} / \mathrm{min}$. As schematically shown in Fig. 1a, a bone simulating block was held in a fixture, which connected to a Kistler Piezoelectric Dynamometers (Type 9273) for the measurement of axial insertion force. A k-type thermocouple was placed in a $1 \mathrm{~mm}$ in dimeter and $2 \mathrm{~mm}$ deep hole of the insertion material, situated at a distance of $5 \mathrm{~mm}$ from the axis of the inserted pin, connected with the Pico USB TC-08 data logger.

The pin was inserted a distance of $23 \mathrm{~mm}$ without predrilling through the plate at a rotational speed of $50 \mathrm{rpm}$. The applied axial force needed to achieve this fixed insertion speed and the temperature increase during insertion were continuously recorded by the Kistler Piezoelectric Dynamometers and the Pico USB TC-08 data logger, individually. The insertion performance was evaluated by determining the maximum axial insertion force and the maximum temperature increase during insertion. Post-insertion examination was conducted to identify the wear of CCT treated and untreated pins using both Toolmakers optical microscopy and FEI Quanta 3D FEG FIB-SEM.
Fig. 1 A schematic of a the pin insertion set up and $\mathbf{b}$ experimental method for the assessment of the antimicrobial efficacy of insertion Ti pins

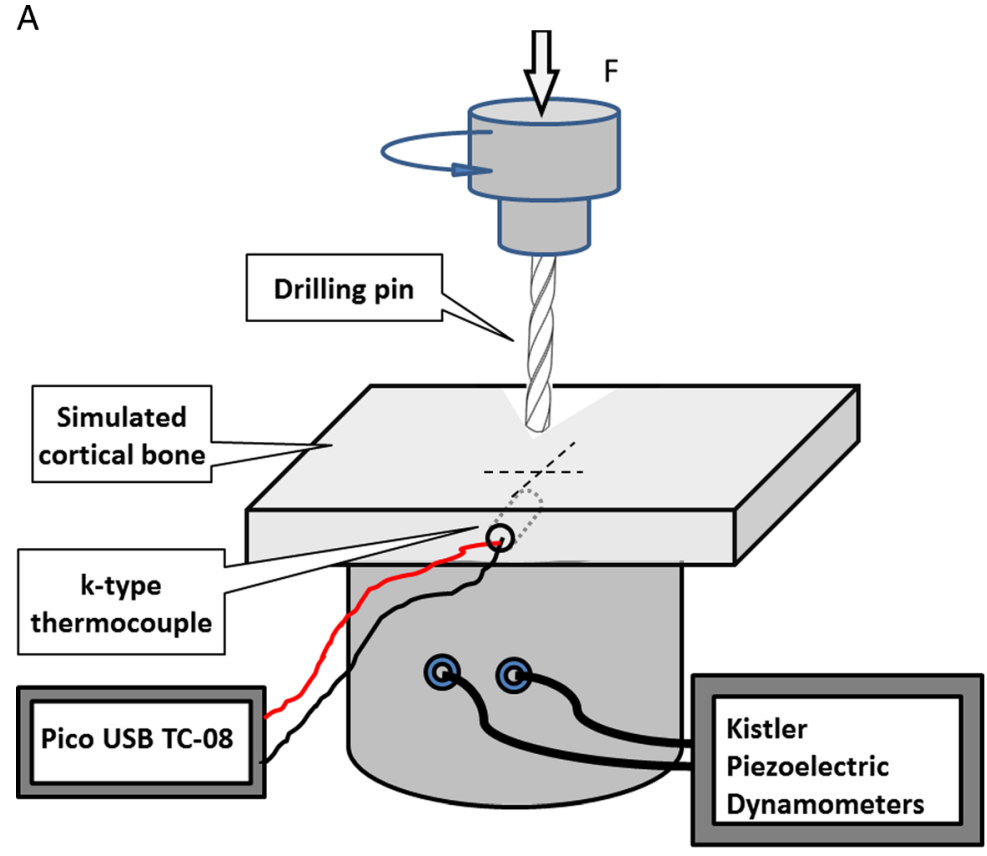

B

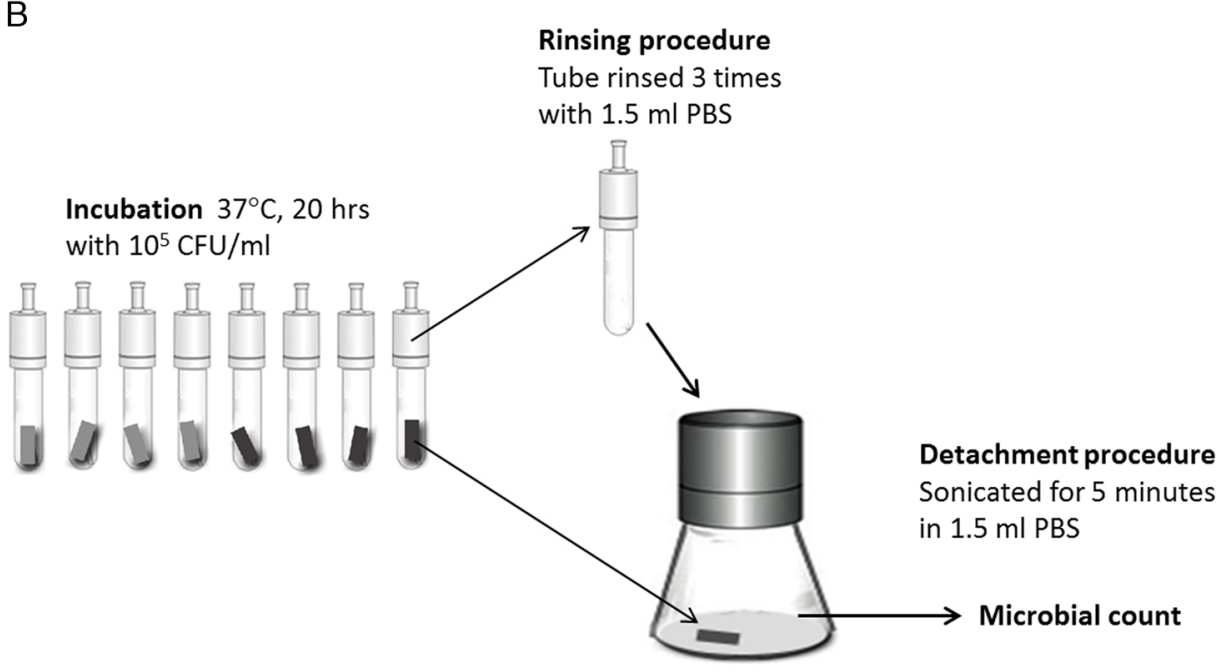




\subsection{Antibacterial test}

Based on the method of Furkert et al. [7], the antibacterial activity of untreated and CCT treated Ti6Al4V pins $5 \mathrm{~mm}$ in diameter and $8 \mathrm{~mm}$ in length cut from the head of the fixation pins $(n=4)$, were tested with Staphylococcus aureus (S. aureus) NCTC 6571. The bacteria were cultured in sterile tryptone soya broth (Oxoid, UK) overnight at $37^{\circ} \mathrm{C}$ in a shaking incubator at $100 \mathrm{rpm}$. Serial dilutions were made to achieve a suspension of $10^{5}$ colony forming units per $\mathrm{ml}(\mathrm{cfu} / \mathrm{ml})$ in a sodium chloride peptone broth $\mathrm{pH} 7.0$ (SCPB) mix. Four untreated (control) and four CCT treated Ti6Al4V pins ( $5 \mathrm{~mm}$ diameter, $8 \mathrm{~mm}$ length), were sterilised by autoclaving $\left(120^{\circ} \mathrm{C}, 1 \mathrm{bar}\right.$ pressure) and then completely immersed in $1.5 \mathrm{ml}$ of the bacterial suspension in individual sterile microfuge tubes. The tubes were incubated at $37^{\circ} \mathrm{C}$ for $20 \mathrm{~h}$ without shaking.

Following incubation the bacterial suspension was discarded from the tubes containing the fixation pins and they were rinsed three times with $1.5 \mathrm{ml}$ of sterile Phosphatebuffered saline (PBS), to remove low surface-adherent bacteria. The samples were then sonicated for $5 \mathrm{~min}$ in 1.5 $\mathrm{ml}$ PBS in a VitaSonic In-ceram sonic bath to detach any high surface-adherent bacteria. $1 \mathrm{ml}$ of this suspension was then diluted $10^{-2}$ in PBS and $0.1 \mathrm{ml}$ aliquots were plated in triplicate on TSA to determine the viable counts of the recovered bacteria. The results are expressed as the mean \pm standard deviation (SD). A schematics of the experimental method for the assessment of the antimicrobial efficacy of insertion Ti pins is shown in Fig. 1b.

\section{Results}

\subsection{Microstructure characterisation of CCT treated coupon samples}

Typical SEM images of surface morphology and fractured cross-sectional microstructures of the CCT treated Ti6Al4V samples are shown in Fig. 2. It was observed that the specimens were all covered by oxides. When treated at $550{ }^{\circ} \mathrm{C}$ (up to $480 \mathrm{~h}$ ) and $600{ }^{\circ} \mathrm{C}$ (up to $85 \mathrm{~h}$ ), the oxides are smooth and fine roundish shaped, as is typified in Fig. 2a. When temperatures increased to $700{ }^{\circ} \mathrm{C}$, less than $10 \mathrm{~h}$ treatment resulted a rough surface of the specimen with sharp-angled oxide particles (see Fig. 2c). Further increase the treatment temperatures over $800{ }^{\circ} \mathrm{C}$, less than half an hour treatment, the surface of the specimen was coved by blistered large granular and whisker oxides as evidence in Fig. 2e. SEM images of Fig $2 b, d$ and $f$ revealed the oxide layer structure and the bonding state of 600,700 and $850{ }^{\circ} \mathrm{C}$ treated samples. It can be clearly seen that oxides formed at $600{ }^{\circ} \mathrm{C}$ are dense, well bonded/adhered to the substrate.
Conversely, stratification of the oxide layer and weak bond to the substrate were observed when samples treated at 700 ${ }^{\circ} \mathrm{C}$, as revealed in Fig. 2d. Pronounced stratification and spallation of the oxide layer from $800{ }^{\circ} \mathrm{C}$ and above treated samples was observed, which was caused by the interfacial stresses [25]. Based on the above observation, treatment conditions in terms of temperature and time was chosen as $650{ }^{\circ} \mathrm{C}$ and $85 \mathrm{~h}$. Further microstructure characterisation detailed in the rest part of this section is for the coupon samples treated under this condition. Figure 3 a reveals the cross-sectional layer structure of the optimal CCT treated sample and the corresponding GDOES composition-depth profiles is shown in Fig. 3b. High amount of oxygen was introduced to the surface and levelled within $2 \mathrm{um}$ depth from the surface before a considerable drop in the diffusion zone (Fig.3b). The X-ray diffraction (XRD) patterns of the CCT treated and untreated Ti6Al4V samples are shown in Fig. 4 and it can be seen that the XRD pattern of the untreated material (Fig. 4b) is dominated by the alpha $\mathrm{Ti}$ peaks with a few weak peaks for beta Ti. After CCT treatment, some additional peaks appeared which can be identified as $\mathrm{TiO}_{2}$ rutile (Fig. 4a). The relative intensity of these rutile peaks is much lower than that of alpha because the X-ray penetration depth is estimated to be about $10 \mu \mathrm{m}$, which is much larger than the thickness of the surface rutile layer $(\sim 2 \mu \mathrm{m})$. In addition, no peaks from beta $\mathrm{Ti}$ were identified mainly because of the inward diffusion of the alpha stabiliser oxygen. XTEM observation revealed features of the surface oxide layer structure as shown in Fig. 5. It can be seen that the oxide layer composed of two sublayers: an inner layer of fine columnar grains, as evidence by ring patterns (Fig. 5c) and an outer layer of well-growing equal-axis grains. Analysis of the Selected area diffraction (SAD) patterns taken from inner and outer sublayers identified the rutile $\mathrm{TiO}_{2}$ phase, as indexed in Figs. 5b,c. The SAD pattern taken from the adjacent substrate (Fig. $5 \mathrm{~d}$ ), revealed an expanded HCP structure of $\alpha-\mathrm{Ti}(\mathrm{O})$. The interface between the oxide layer and the adjacent oxygen diffusion zone, appeared dense and without voids.

\subsection{Mechanical and tribological properties of CCT treated coupon samples}

Microhardness profile cross the diffusion zone for $600{ }^{\circ} \mathrm{C}$, $85 \mathrm{~h}$ treated sample is shown in Fig. 6a and the thickness of the hardened layer was estimated from the profile to be 15 $\mu \mathrm{m}$ with a near-surface hardness of about $900 \mathrm{HK}_{0.015}$, which is about three times that of untreated material. This is because in addition to the formation of a thin surface oxide layer about $2 \mu \mathrm{m}$ (Fig. 3a), an oxygen diffusion zone was also formed during the CCT treatment and produced effective solid solution hardening by the oxygen [23]. 
Fig. 2 Typical SEM images of surface morphology (left) and fractured cross-sectional (right) microstructures of the CCT treated Ti6Al4V samples: $(\mathbf{a}, \mathbf{b})$ $600^{\circ} \mathrm{C}, 85 \mathrm{~h} ;(\mathbf{c}, \mathbf{d}) 700{ }^{\circ} \mathrm{C}, 20 \mathrm{~h}$ and $(\mathbf{e}, \mathbf{f}) 800^{\circ} \mathrm{C}, 20 \mathrm{~h}$
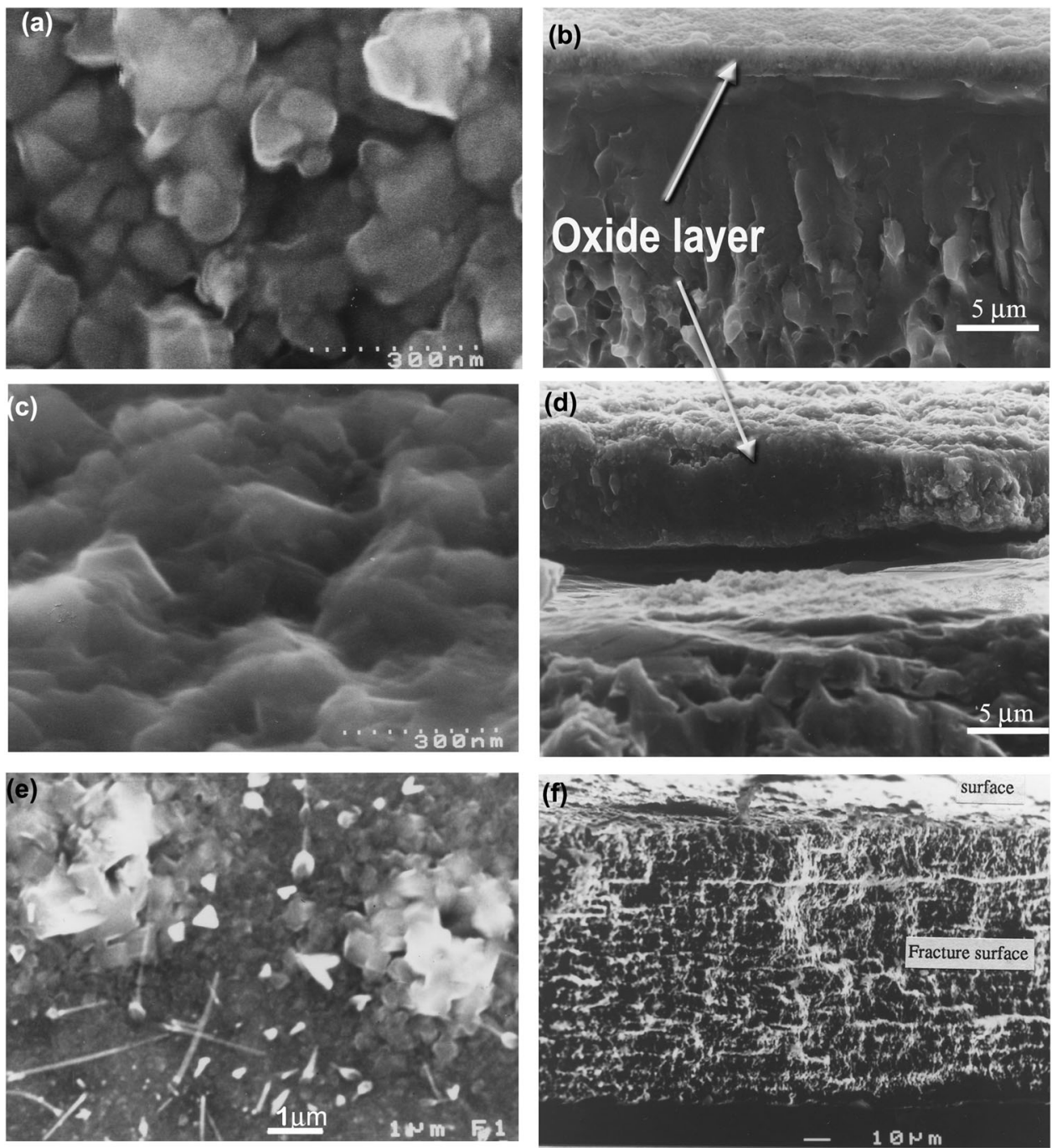

Because the surface oxide layer is very thin, nanoindentation was used to probe the mechanical properties of the surface oxide layer. The load-unload vs. depth hysteresis curves recorded during the nanoindentation tests for asreceived and CCT treated specimens are shown in Fig. 6b. It can be seen clearly that the CCT treated sample exhibits a much shallower penetration depth and a higher elastic recovery than the as-received sample. The nano-hardness $(\mathrm{H})$ and the Young's modulus (E) of the rutile oxide layer measured to be $10.5 \pm 0.5 \mathrm{GPa}$ and $146.7 \pm 1.2 \mathrm{GPa}$, respectively, while for the as-received sample, the $\mathrm{H}$ and $\mathrm{E}$ are 4.3 $\pm 0.4 \mathrm{GPa}$ and $114.3 \pm 1.3 \mathrm{GPa}$, respectively. The ratio of $\mathrm{H} /$ $\mathrm{E}$ is increased from 0.029 for untreated sample to 0.071 for the CCT treated sample. This indicates that compared with the untreated material the rutile oxide layer possessed a much higher capacity for elastic deformation and hence a reduced tendency for adhesive wear and scuffing [23].

Scratch tests carried out on the CCT treated samples revealed that no clear cracking occurred at the beginning; then, conformal cracking started to occur when the load increased to about $40 \mathrm{~N}$ (Fig. 7a); but the oxide layer remained adherent to the substrate without flaking until it was entirely removed when the critical load about $70.5 \pm$ $2.2 \mathrm{~N}$ was exceeded and the monitored friction increased rapidly. Even at the end of scratch test where severe pile-up of the substrate material is clearly evidenced, neither flaking nor spalling was appreciable (Fig. 7b). This indicates that the oxide layer formed by in-situ conversion remains adherent and failure was mainly caused by excessive plastic deformation in the substrate [26].

\subsection{Biomechanical properties of the self-drilling/self- tapping pins}

The typical recorded axial force needed to achieve the insertion distance of $23 \mathrm{~mm}$ under the fixed insertion speed of $25 \mathrm{~mm} / \mathrm{min}$ as a function of the insertion time is exemplified in Fig. 8a. It can be seen that the applied axial force increased almost linearly and smoothly before it reached the maximum value when the self-drilling/self-tapping pin was 


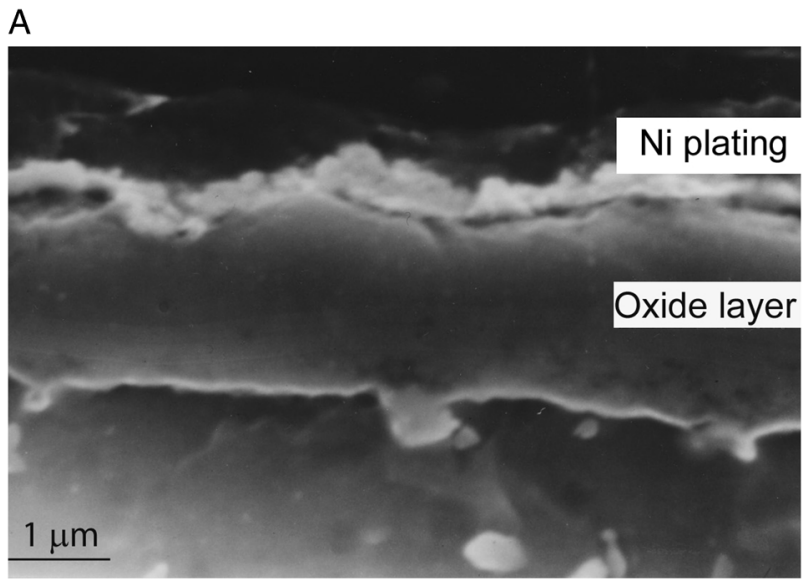

B

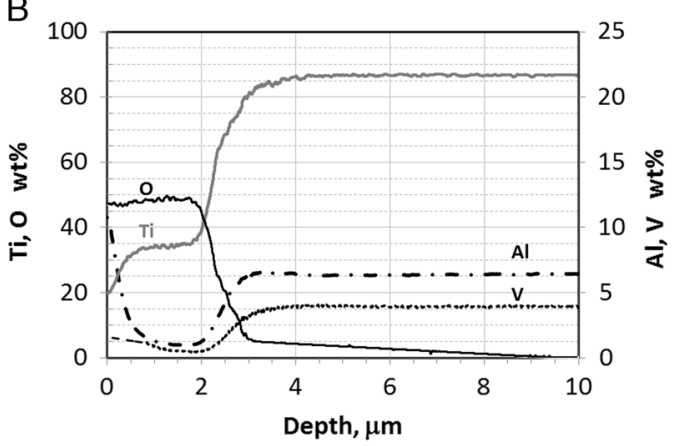

Fig. 3 a SEM image of cross-sectional layer structure and b GDOES depth chemical composition profiles of optimal CCT treated $\left(600{ }^{\circ} \mathrm{C}\right.$, $85 \mathrm{~h})$ Ti6Al4V alloy

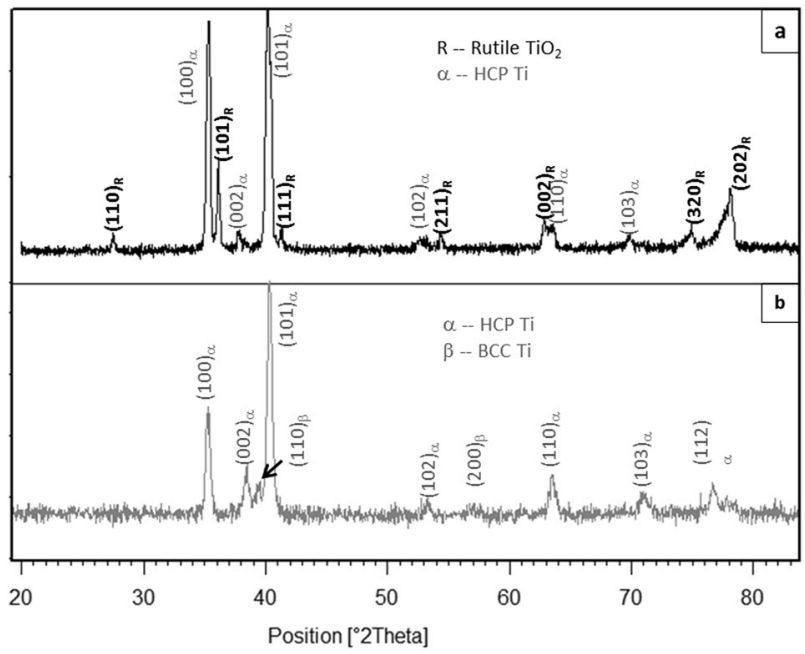

Fig. 4 XRD patterns of a CCT treated and $\mathbf{b}$ untreated Ti6Al4V alloy, showing formed rutile $\mathrm{TiO}_{2}$ on the treated sample

driven into the bone simulation material; then it reduced relatively slowly with some fluctuation when the pin went through the bone simulation block; and finally it rapidly reduced before it flattened at a low value after the pin fully went through the block. The temperature variation during the insertion tests was recorded by the Kistler Piezoelectric
Dynamometers and the Pico USB TC-08 data logger, which is shown in Fig. 8b. It is revealed that the temperature of the simulated cortical bone started to increase after about $5 \mathrm{~s}$ and reached to a maximum value at the insertion time of $10 \mathrm{~s}$ and then reduced slowly to room temperature after about $30 \mathrm{~s}$. Compare with the axial force variation during the insertion, it can be seen that although the trends are the same, the recorded temperature showed hysteresis in relative to the insertion force recorded. This phenomenal is largely caused by the thermal transfer in the bone simulation material as the thermal couple was set at a distance of $5 \mathrm{~mm}$ from the axis of the inserted pin (Fig. 1a) with a small gap of $2.5 \mathrm{~mm}$ between the tip of the thermal couple and the surface of the pin. The most important biomechanical characteristic is the maximum insertion force for self-drilling/self-tapping and the results are summarised in Fig. 9a. It can be seen that the maximum insertion force for self-drilling/self-tapping can be reduced from $192 \mathrm{~N}$ for untreated pins to $182 \mathrm{~N}$ for the CCT treated pins. The maximum temperature recorded during the insertion period reduced from $31.2 \pm 1.0^{\circ} \mathrm{C}$ when using the untreated pins to $26.1 \pm 0.5^{\circ} \mathrm{C}$ (Fig. 9b). These data are mean values from 3 sets of pins to ensure reliability.

Figure 10a shows the self-drilling/self-tapping pins before and after the CCT treatment. After the insertion tests, the drilling blades and the threads of the pin were observed using a Toolmakers microscope. It is clear that wear occurred to the drilling blades of the untreated pins after insertion test as evidenced by comparing the width of the cutting edge before (Fig. 10b) and after (Fig. 10c) the test; in contrast, no appreciable wear was observed from the cutting edge for the CCT treated pins after the insertion test under the Toolmakers microscope. This is further proved by SEM images in Fig. 11 where a flat strip at the edge of the drilling blade with parallel wear grooves can be clearly seen for the untreated pin (denoted by arrows in Fig. 11a) and severe abrasive wear occurred to the cutting edge of the blade during the insertion test. On the other hand, the cutting edge of the CCT treated pin is still sharp after testing (denoted by an arrow in Fig. 11b) without clear wear grooves under the given magnification. Similar results have also been obtained when examining other parts of the pins after the insertion test. For example, the top of all the threads on the untreated pins were worn as evidenced by the thick wear grooves (Fig. 12a) but only a few shallow wear grooves or scratches were observed on the top of the threads for the CCT treated pins after testing (Fig. 12b). Clearly, severe abrasive wear was observed on the tested untreated surface as evidenced by the dense and deep abrasive wear grooves. This is caused by the relatively short fibres within the bone substitute blocks although the overall hardness of the composite block (estimated to be $1.1 \mathrm{GPa}$ based on the compressive strength) is lower than the hardness of untreated material $(3.4 \mathrm{GPa})$. The different wear behaviour 

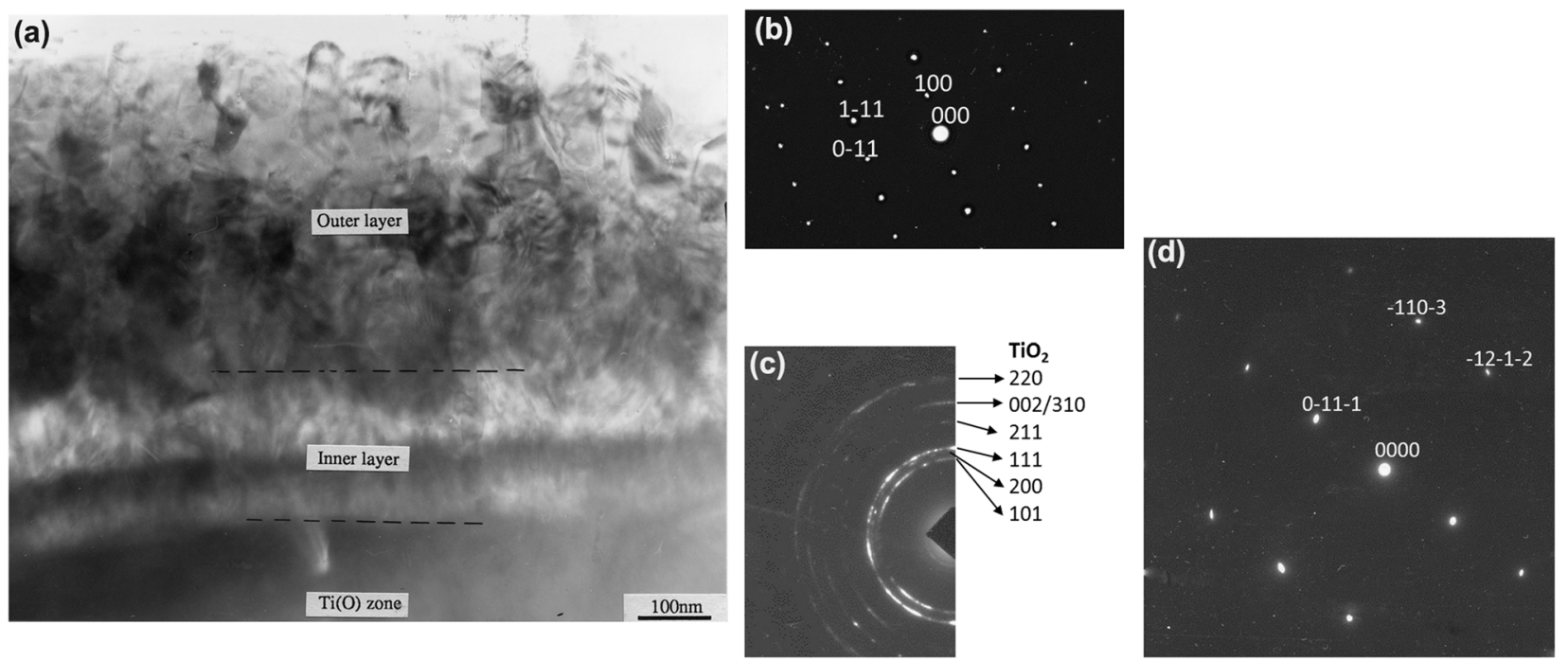

Fig. 5 XTEM microstructure a of the surface oxide layer and corresponding SAD patterns taken from $\mathbf{b}$ an outer layer $\mathrm{TiO}_{2}$ grain, $\mathbf{c}$ inner layer of fine columnar $\mathrm{TiO}_{2}$ grains and $\mathbf{d}$ substrate diffusion zone of $\alpha$ - $\mathrm{Ti}(\mathrm{O})$

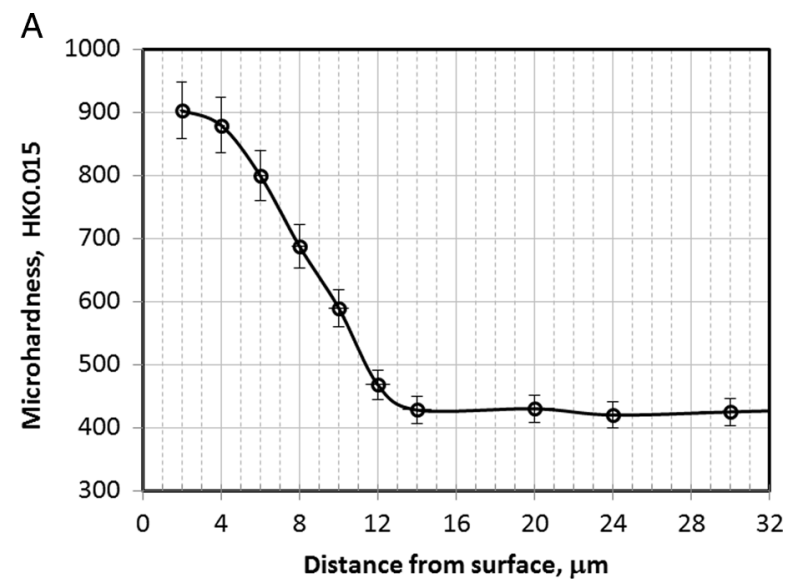

B

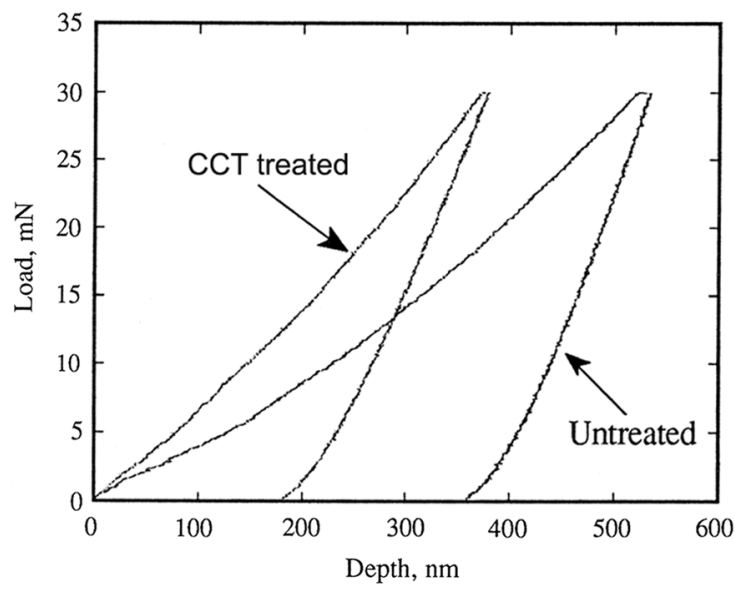

Fig. 6 a Knoop harness profile cross the diffusion zone for $600{ }^{\circ} \mathrm{C}, 85$ h CCT treated sample b nano-indentation load-unload verses depth hysteresis curves for as-received and CCT treated specimens between the CCT treated and untreated pin surfaces could be attributed to the larger difference in hardness between the CCT treated (10.5 GPa) and the untreated (3.4 GP) surfaces. This is because the abrasive wear resistance of a material is inversely proportion to its surface hardness.

\subsection{Anti-bacterial efficacy}

Sections cut from the untreated (Un Ti) and the ceramic conversion treated (CCT Ti) fixation pins were subjected to the antibacterial test procedure as described in Section 2.5, Fig. 1b. The control bacterial suspension contained about $7.6 \times 10^{8} \mathrm{cfu} / \mathrm{ml}$ of $S$. aureus post-incubation. The experimental results revealed that viable counts of the bacteria recovered from the pins indicated that there was a significant reduction, $P<0.01$ (0.0024), in the number of cfu recovered from the ceramic conversion treated pins (CCT Ti) compared to the untreated pins ( $\mathrm{Un} \mathrm{Ti}$ ) of approximately $50 \%$ (Fig. 13). This clearly indicates that the ceramic conversion can effectively improve the antibacterial efficacy of Ti6Al4V fixation pins.

\section{Discussion}

\subsection{Improved biomechanics}

As has been reported above, the ceramic conversion treatment can effectively reduce the insertion force (Fig. 9a) of Ti6Al4V fixation pins. This significantly improved biomechanical behaviour of the Ti6Al4V fixation pins by the ceramic conversion treatment should be attributed to the 
Fig. 7 SEM BS images showing a typical conform cracking and at the end of the scrach b neither flaking nor spallation
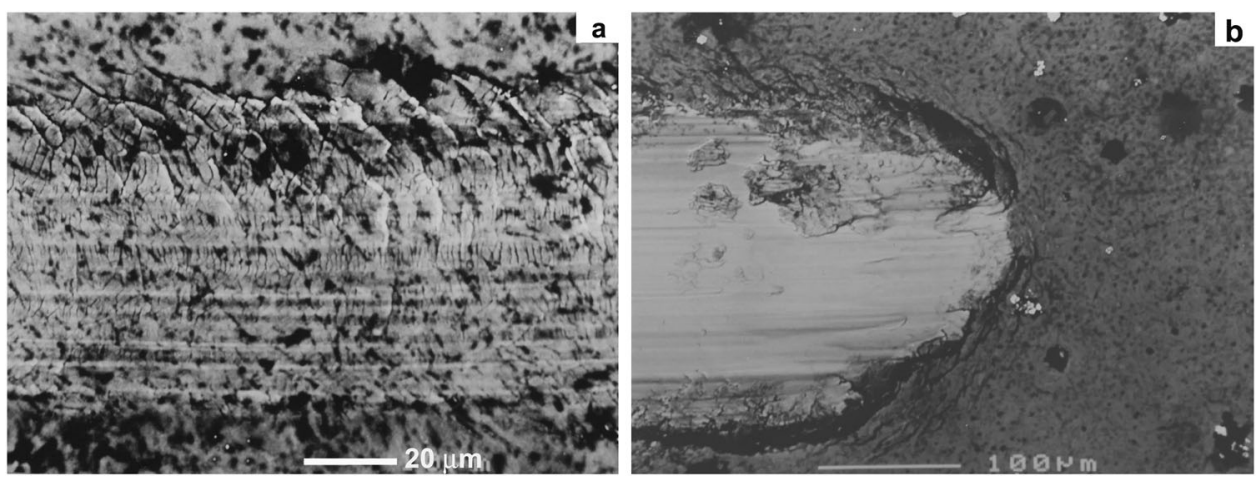

Fig. 8 Recorded a maximum change against the insertion time under the fixed insertion speed of $25 \mathrm{~mm} / \mathrm{min}$ to SAWBONES ${ }^{\circledR}$ cortical bone plates (a)

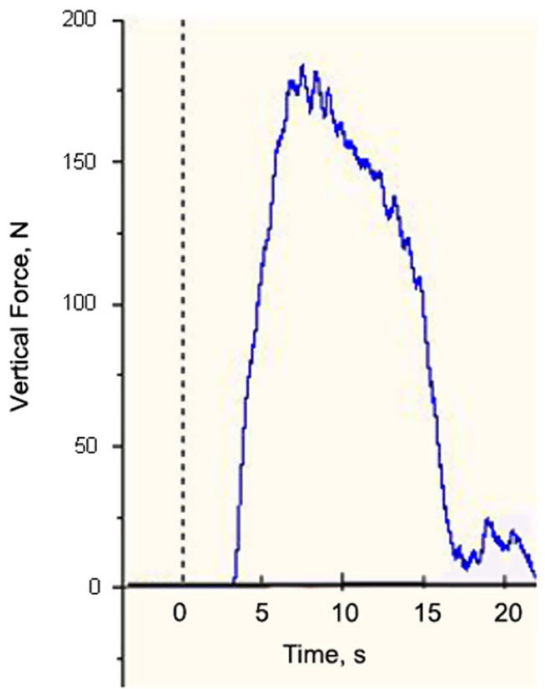

(b)

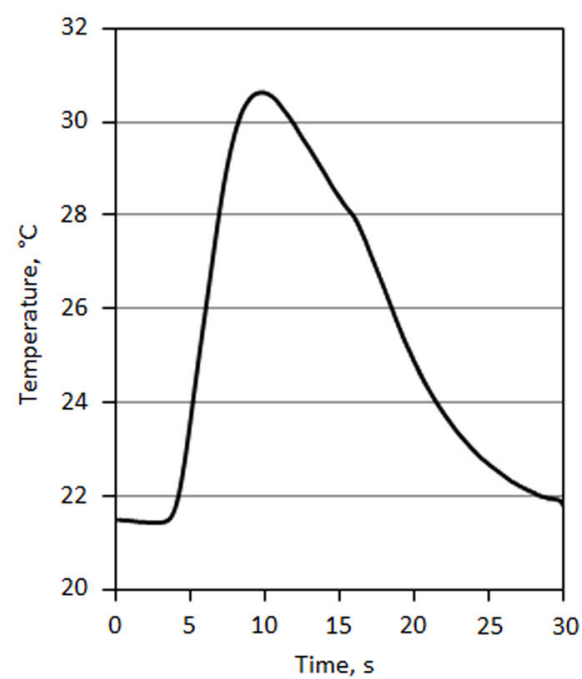

significantly improved bio-tribological properties of the titanium pins in terms of reduced friction and increased hardness. As has been clearly shown in Fig. 11, after inserting into the simulated cortical bone, severe wear has occurred to the cutting edge (as arrowed in Fig. 11a) as evidenced by the fact that the cutting edge become blunt with a platoon about $100 \mu \mathrm{m}$ wide on the top; on other hand, the cutting edge of the CCT treated pins retains its original sharp edge with no appreciable wear (Fig. 11b).

The poor biomechanical and bio-tribological properties of Ti6Al4V pins are closely related to the low hardness, the electronic structure and crystal structure of titanium. This is because the hardness of the untreated Ti6Al4V is low (about $350 \mathrm{HV}$ ) compared with hardened steel (about 700-800HV). Hence abrasive wear will occur when drilling relatively hard simulated cortical bone (Figs. 11a and 12a) since the abrasive wear resistance of a surface is proportional to its hardness [19]. In addition, it is also known that $\mathrm{Ti}$ has strong adhesive wear and galling tendency mainly due to its special electronic and crystal structure [20]. The experimental results reported in Section 3.2 have shown that

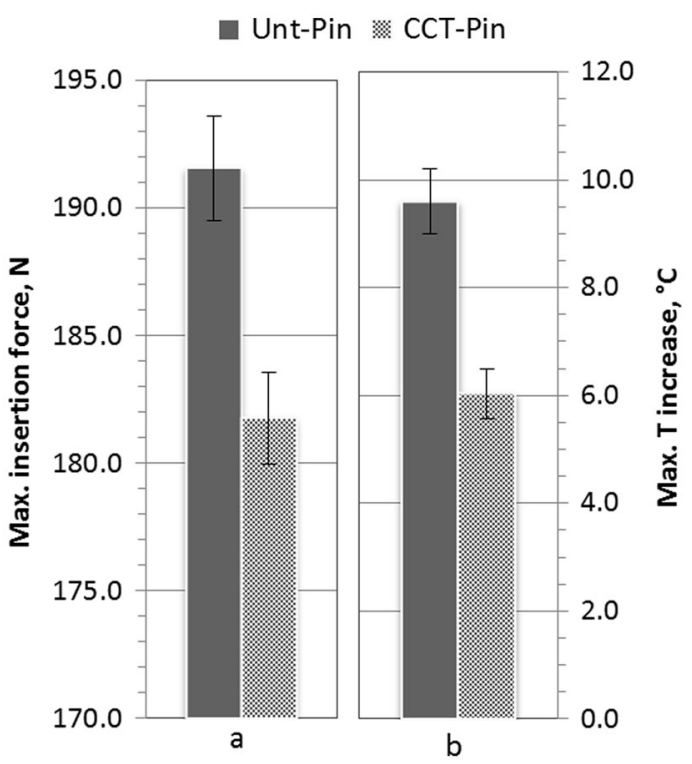

Fig. 9 Comparison of a maximum insertion forces and $\mathbf{b}$ maximum temperature increase for untreated and CCT treated self-drilling/selftapping pins inserting to SAWBONES ${ }^{\circledR}$ cortical bone plates 
the $\mathrm{H} / \mathrm{E}$ ratio of the Ti6Al4V pins, which is a measure of the resistance to adhesive wear and galling, increased about 1.5 times after the CCT treatment.
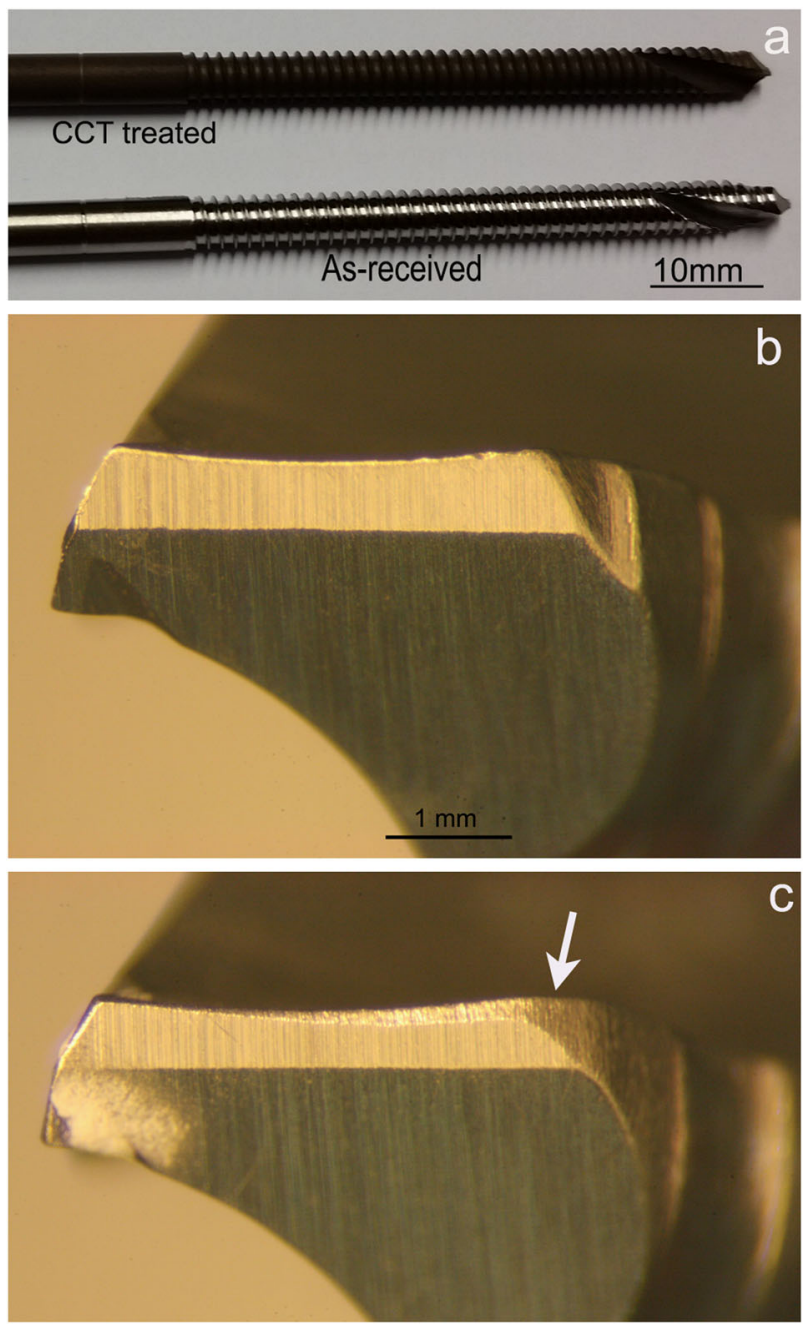

Fig. 10 Optical images of a untreated and CCT treated self-drilling/ self-tapping pin; untreated drilling blades $\mathbf{b}$ before and $\mathbf{c}$ after the insertion tests (The arrow denotes the wear of the cutting edge)
As shown in Figs. 2-6, the ceramic conversion treatment can convert in-situ, the Ti surface into $\mathrm{TiO}_{2}$ rutile ceramic layer with a hardness of around $1050 \mathrm{HV}$, which is about three times the hardness of the untreated material. Hence, it is expected both abrasive wear and adhesive wear of $\mathrm{Ti}$ could be reduced by the formation of the hard ceramic layer due to significantly increased hardness and the change of the nature of the surface from Ti to ceramic, respectively. In addition, this hard ceramic layer is in-situ converted and hence the concerns over the de-bonding or delamination of deposited ceramic coatings from the substrate can be addressed by the in-situ conversion approach. This has been proved by the scratch results shown in Fig. 7 .

Most importantly, the untreated TiAl6Al4V is relatively soft and it has been widely reported that thin ceramic coating on a weak substrate can be easily damaged due to the well-known "thin egg-shell effect"-without sufficient mechanical support from the substrate, this hard coating will collapse [17]. In this research, TiAl6Al4V pins were ceramic conversion treated and in addition to the formation of a thin rutile layer on the top, oxygen also diffused into the subsurface (Figs. 3, 5), thus increasing the hardness (Fig. 6a) via solid solution hardening.

In short, it is the ceramic conversion induced surface hard ceramic layer supported by an oxygen hardened case beneath and the resulting significantly increased hardness, bonding strength and load supporting capacity of TiA$16 \mathrm{Al} 4 \mathrm{~V}$ pins that effectively improved the biomechanical and bio-tribological properties of TiAl6Al4V pins.

\subsection{Clinical indication and future work}

The antibacterial properties demonstrated by the treated titanium pins could be very useful for reducing the high levels of pin site infections (as high as $30 \%$ ) seen following external fixation. This ranges from frank osteomyelitis to
Fig. 11 SEM images of the Ti pins after the insertion tests: a untreated and $\mathbf{b}$ CCT treated drilling blades (denoted by arrows)
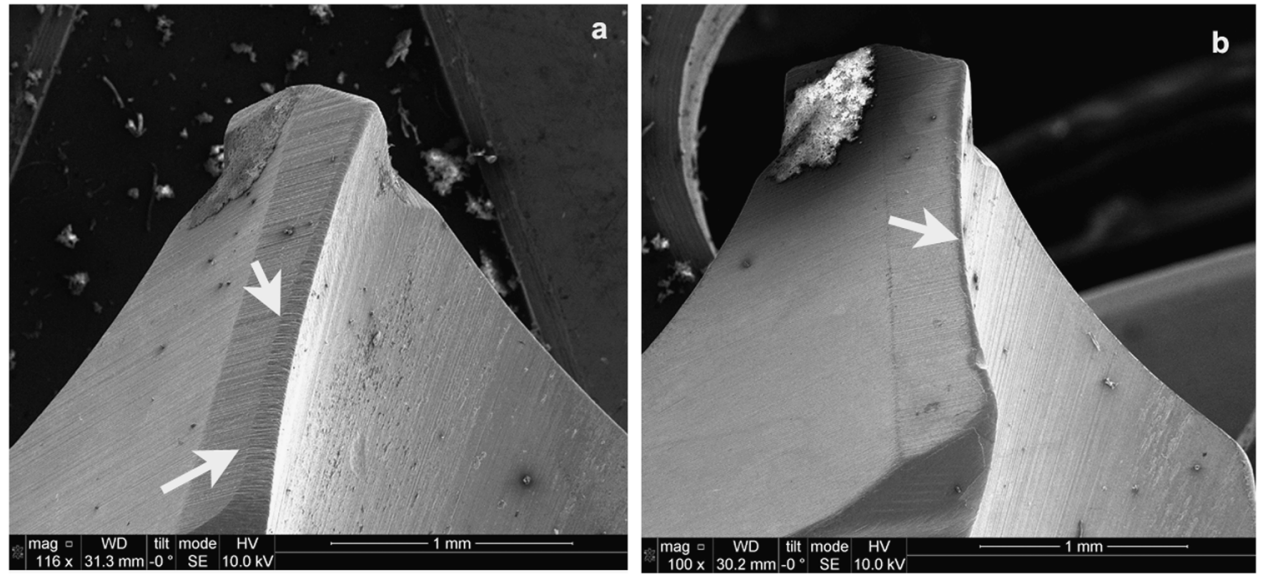
Fig. 12 SEM images taken from the top of the Ti pin threads, a untreated and $\mathbf{b}$ CCT treated

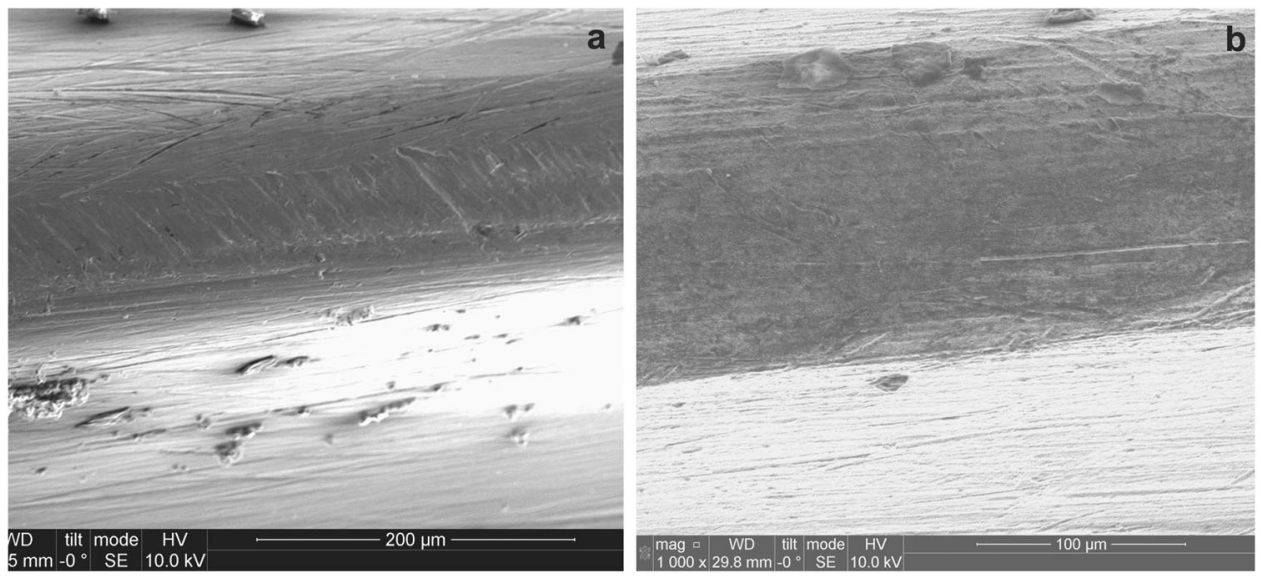

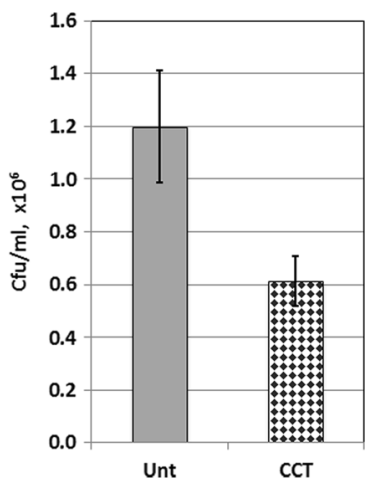

Fig. 13 S. aureus recovered from fixation pins after $20 \mathrm{~h}$ incubation, following rinsing and sonication in $1.5 \mathrm{ml}$ PBS. Results are expressed as $\mathrm{cfu} / \mathrm{ml} \times 10^{6} \pm \mathrm{SD},(n=4)$

low grade infections which, nevertheless still cause loosening of pins at the bone-pin interface thereby compromising the structural rigidity of the fixation.

The antibacterial properties of $\mathrm{TiO} 2$, especially in the form of anatase following photoactivation with UV light, are well documented. Although most literature concerns the effects of anatase, rutile has a higher intrinsic photoactivation capacity and rutile nanoparticles showed a higher antimicrobial activity against E.coli [27]. The killing mechanism is thought to involve the production of destructive hydroxyl radicals, reactive oxygen intermediates and hydrogen peroxide. The reason for the antibacterial effect of our treated material in the absence of UV radiation is not yet entirely clear but studies have shown that photoactivation of both anatase and rutile can be achieved by short exposure to fluorescent light of wavelengths found in room lights [28]. Our results are consistent with those of a previous study (without UV irradiation) which showed that adhesion of the Gram positive bacterium Streptococcus gordonii was reduced by approximately $50 \%$ on a rutile surface compared with anatase [29]. However the photoactivation effect depends on many factors including surface area, grain size and crystal dimensions $[27,28]$. Independent of any possible photoactivation effect, bacterial adherence is dependent on several factors including surface area, surface energy and the coefficient of friction, which is reduced on the modified pin surface. The reason for reduced numbers of bacteria on our modified surface clearly merits further study with more bacterial strains, given the potential clinical applications.

By reducing the number of pin site infections, this surface treatment may reduce the need for antibiotics. This can be in the form of systemic antibiotics used to treat pin site infections or antibiotic impregnated coatings that have been developed for ex-fix pins. This would in turn reduce the problem of antibiotic resistance, which is currently a major issue facing the medical community. Moreover, as ceramic conversion essentially involves the oxidation of titanium it does not have the potentially toxic effects caused by the leaching of heavy metal ions from other coatings such as silver [8].

The reduced force needed to insert the ceramic conversion treated pins, caused by an increase in surface hardness, leads to a smaller rise in temperature in the adjacent soft tissues and thereby potentially causing less bone and soft tissue necrosis. This in turn provides less dead tissue around the pin sites which would otherwise be an excellent medium for bacterial colonisation. Furthermore, less necrotic bone surrounding the pin would help bio-integration and potentially lead to a lower incidence of pin loosening.

Future work could look at exploiting the inherent photocatalytic activity of titanium oxide. Titanium oxide surfaces are known to have increased antibacterial properties following exposure to UV radiation [10]. Titanium oxide surfaces are thought to kill bacteria by the breakdown of bacterial cell wall and membrane by reactive oxygen surfaces. UV irradiation of the surfaces causes an increase in free radicals thereby increasing the antibacterial effect. 
In addition, future work could look at the antibacterial effect for other Gram positive and Gram negative bacteria that are known to cause pin site infections such as Staphylococcus epidermidis, Escherichia coli and Pseudomonas aeruginosa [30].

Ultimately, the aim will be to see if there is a clinically demonstrable and significant benefit. To this end, we will first need to perform animal trials and if results are favourable, then to proceed to a randomised controlled trial. Finally, the ceramic conversion technique described is a very inexpensive treatment, making it a very commercially viable process compared to other surface treatments/coatings such as hydroxyapatite coatings which are prohibitively expensive.

\section{Summary and conclusions}

In this study, an advanced surface engineering technology based on cost-effective and fully environmentally friendly CCT has, for the first time, been successfully applied to TiAl4V external fixation pins. This study demonstrates that the surface of TiAl4V external fixation pins can be converted into a $\mathrm{TiO}_{2}$ rutile layer ( $2 \mu \mathrm{m}$ in thickness), which is supported by an oxygen hardened case $(\sim 15 \mu \mathrm{m}$ in thickness). Scratch testing revealed strong bonding between the surface rutile layer and the hardened case beneath due to the in-situ conversion nature. The surface hardness of Ti pins increased from 320 to $1050 \mathrm{HV}$ following the CCT treatment.

When inserting into high density bone simulation material, the maximum insertion forces were reduced from 192 $\mathrm{N}$ when using the untreated pins to $182 \mathrm{~N}$ when the CCT treated pins were tested; the maximum temperature recorded during the whole insertion test was reduced from $31.2^{\circ} \mathrm{C}$ for the untreated pins to $26.1^{\circ} \mathrm{C}$ for the CCT treated pins. Post-testing SEM examination of the tested pins revealed that severe wear occurred to the cutting edge of the untreated Ti pins whilst no appreciable wear was observed for the CCT treated pins mainly due to the improved surface hardness by rutile layer, good bonding strength by in-situ conversion and enhanced load bearing capacity by the oxygen diffusion hardened case. The antibacterial test also revealed that the bacterial viable counts of the bacteria recovered from the pins indicated that there was a significant reduction, $P<0.01(0.0024)$, in the number of cfu recovered from the ceramic conversion treated pins compared to the untreated pins of approximately $50 \%$.

The promising experimental results encourage the exploitation of the inherent photocatalytic activity of titanium oxide to further enhance the anti-bacterial efficacy of the CCT treated Ti pins. In addition, animal trials could be performed before proceeding to a randomised controlled trial.

\section{Compliance with ethical standards}

Conflict of interest The authors declare that they have no competing interests.

Open Access This article is distributed under the terms of the Creative Commons Attribution 4.0 International License (http:// creativecommons.org/licenses/by/4.0/), which permits unrestricted use, distribution, and reproduction in any medium, provided you give appropriate credit to the original author(s) and the source, provide a link to the Creative Commons license, and indicate if changes were made.

\section{References}

1. Austin AT, Fragomen R, Rozbruch S. The mechanics of external fixation. HSSJ. 2007;3:13-29.

2. Wikenheiser MA, Market MD, Lewallen DG, et al. Thermal response and torque resistance of five cortical half pins under simulated insertion technique. J Orthop Res. 1995;13:615-9.

3. Davis JR, ed. Handbook of materials for medical devices. Materials Park: ASM International; 2003. p. 27-28.

4. Massè A, Bruno A, Bosetti M, Biasibetti A, Cannas M, Gallinaro P. Prevention of pin track infection in external fixation with silver coated pins: clinical and microbiological results. J Biomed Mater Res. 2000;53:600-4.

5. Wickens DJ, West G, Kelly PJ, Verran J, Lynch S, Whitehead KA. Antimicrobial activity of nanocomposite zirconium nitride/ silver coatings to combat external bone fixation pin infections. Int J Artif Organs. 2012;35:817-25.

6. Campoccia D, Montanaro L, Arciola CR. A review of the biomaterials technologies for infection-resistant surfaces. Biomaterials. 2013;34:8533-54.

7. Furkert FH, Sörensen JH, Arnoldi J, Robioneck B, Steckel H. Antimicrobial efficacy of surface-coated external fixation pins. Curr Microbiol. 2011;62:1743-51.

8. Albers CE, Hofstetter W, Siebenrock KA, Landmann R, Klenke FM. In vitro cytotoxicity of silver nanoparticles on osteoblasts and osteoclasts at antibacterial concentrations. Nanotoxicity. 2013;7: $30-6$.

9. Jennison T, McNally M, Pandit H. Review- Prevention of infection in external fixation pin sites. Acta Mater. 2014;10:595-603.

10. Visai L, De Nardo L, Punta C, Melone L, Cigada A, Imbriani M, Arciola CR. Titanium oxide antibacterial surfaces in biomedical devices. INt J Artif Organs. 2011;34:929-46.

11. Kirmanidon Y. et al. New Ti-alloys and surface modifications to improve the mechanical properties and the biological response to orthopaedic and dental implants: a review. BioMed Res Int. Volume 2016, Article ID 2908570, 21 pages, 2016. doi:10.1155/ 2016/2908570.

12. Huo K, Gao B, Fu J, Zhao L, Chu PK. Fabrication, modification and biological applications of anodised $\mathrm{TiO} 2$ nanotube arrays. RCS Adv. 2014;4:17300-24.

13. Sarraf M, Zalnezhad E, Bushroa AR, Hamouda AMS, Rafieerad AR, Basiri-Tabrizi B. Effect of microstructural evolution on wettability and tribological behaviour of $\mathrm{TiO} 2$ nanotubular arrays coated Ti-6Al-4V. Ceram Int. 2015;41:7952-62.

14. Sohrabi H, Tabaian SH, Omidvar H, Sajjadnejad M, Mozafari A. Synthesis of nanostructured $\mathrm{TiO} 2$ coatings by Sol-Gel method: structural and morphological studies. J Synth React Inorg, MetOrg, Nano-Met Chem. 2016;46:414-22.

15. Liu X, Chu PK, Ding C. Surface modification of titanium, titanium alloys and related materials for biomedical applications. Mater Sci Eng R-Rep. 2014;47:49-121. 
16. Rabinowicz E, Kingsbury EP. Lubricant of titanium. Met Prog. 1955;67(5):112-4.

17. Luo X, Li XY. Design and characterisation of a new duplex surface system based on S-phase hardening and carbon-based coating for ASTM F1537 Co-Cr-Mo alloy. Appl Surf Sci. 2014;292:336-44.

18. Wu H, Zhang X, He X, Li M, Huang X, Hang R, Tang B. Wear and corrosion resistance of anti-bacterial $\mathrm{Ti}-\mathrm{Cu}-\mathrm{N}$ coatings on titanium implants. Appl Surf Sci. 2014;317:614-21.

19. Hutchings IM. Tribology: Friction and wear of engineering materials. London: Edward Arnold; 1992.

20. Dong H, Bell T. Enhanced wear resistance of titanium surfaces by a new thermal oxidation treatment. Wear. 2000;238:131-7.

21. Eriksson RA, Albrektsson T. The effect of heat on bone regeneration: An experimental study in the rabbit using the bone growth chamber. J Oral Maxil Surg. 1984;42:705-11.

22. Dong H, Bloyce A, Morton PM and Bell T. Surface oxidation of a titanium or titanium alloy article, US Patent 6210807.

23. Li X, Dong H. Ceramic conversion of titanium-based materials. In: Dong H, editor. Surface engineering of light alloys-aluminium, magnesium and titanium alloys. Cambridge: Woodhead Publishing Ltd; 2010. p. 475-500.
24. Dong H. Surface engineering in sport. Materials in sports equipment. Cambridge: Woodhead Publishing Ltd; 2003. p. 160-95.

25. Bertrand G, Jarraya K, Chaix JM. Morphology of oxide scales formed on titanium. Oxid Met. 1984;21(1):1-19.

26. Burnett PJ, Rickerby DS. The scratch adhesion test: an elasticplastic indentation analysis. Thin Solid Film. 1987;157:18-28.

27. Carattoa V, Aliakbarianc B, Casazzac A, Settia L, Berninib C, Peregoc P, Ferretti M. Inactivation of Escherichia coli on anatase and rutile nanoparticles using UV and fluorescent light. Mater Res Bull. 2013;48:2095-101.

28. Caballero L, Whitehead KA, Allen NS, Verran J. Inactivation of Escherichia coli on immobilized $\mathrm{TiO}_{2}$ using fluorescent light. J Photochem Photobio A Chem. 2009;202:92-8.

29. Barbour ME, Gandhi N, Eel-Turki A, O'Sullivan DJ, Jagger DC. Differential adhesion of Streptococcus gordonii to anataseand rutile titanium dioxide surfaces with and without functionalization with chlorhexidine. J Biomed Mater Res. 2009;90A:993-8.

30. Sharma SK, Gupta JV, Walia I, Sen RK. Prevalence of pin site infection among patients with external skeletal fixation. Nurs Midwifery Res J. 2005;1:124-30. 